\title{
Sexing mammalian spermatozoa and embryos - state of the art
}

\author{
G. E. Seidel, Jr \\ Animal Reproduction and Biotechnology Laboratory, Colorado State University, \\ Fort Collins, CO 80523, USA
}

\begin{abstract}
Methods for sexing preimplantation embryos range from karyotyping to recording speed of development $i n$ vitro. The only method used routinely on a commercial scale is to biopsy embryos and amplify $Y$-chromosome-specific DNA using the polymerase chain reaction. This method is effective for more than $90 \%$ of embryos and is $>95 \%$ accurate. Within males, spermatozoa are essentially identical phenotypically due to: (1) connection of spermatogenic cells by intercellular bridges, (2) transcriptional inactivation of sex chromosomes during meiosis and spermiogenesis, (3) severe limitation of all gene expression during the later stages of spermiogenesis, and (4) coating all spermatozoa with common macromolecules during and after spermiogenesis. One consequence is that no convincing phenotypic difference has been detected between $X$ - and Y-chromosome-bearing spermatozoa. The only consistently successful, nondestructive approach to sexing spermatozoa is to quantify DNA in spermatozoa using a fluorescing DNA-binding dye followed by flow cytometry and cell sorting. X-chromosome-bearing ruminant spermatozoa have about $4 \%$ more DNA compared with $\mathrm{Y}$-chromosome-bearing spermatozoa; accuracy of sorting can exceed $90 \%$ routinely, and sorting rates currently exceed $10^{3}$ live spermatozoa of each sex chromosome composition $\mathrm{s}^{-1}$. Hundreds of apparently normal offspring from a number of species have been produced from sexed semen, some via intrauterine artificial insemination.
\end{abstract}

\section{Introduction}

The most sought-after reproductive biotechnology for humans and animals has been a means to obtain offspring of a pre-determined sex. Potential applications are numerous. For example, in humans, pre-conception selection of the sex of offspring to balance family gender probably would be used widely. Although there are ethical concerns, enabling parents to select the sex of their children would lead to smaller families, ameliorating social ills resulting from overpopulation; in the short term, if the procedure were inexpensive, it would probably be a very effective, non-coercive method for limiting population growth. It certainly would be less objectionable on moral grounds than some current procedures, including selective and non-selective abortion. This technique also can be used to produce girls to avoid X-linked genetic diseases (Levinson et al., 1995).

Applications for farm animals range from the obvious, for example bulls do not produce milk, to the subtle, for example there is less calving difficulty with female calves, due to their smaller size (Burfening et al., 1978). Such technology would be used widely for companion animals, and might even make the difference to whether an endangered species could be rescued from extinction. The focus of this review is on methodology, so applications will not be discussed beyond having given this context for justification. Most applications of sexing concern cattle, so much of the scientific literature concerns this species.

There are several methods for accurate sexing of embryos, but only one method for sexing semen that does not render spermatozoa infertile (Johnson et al., 1989) and can be applied reliably across 
species. There are many reviews of sexing procedures (including: Kiddy and Hafs, 1971; Betteridge et al., 1981; Amann and Seidel, 1982; Seidel, 1988; Amann, 1989; Bondioli, 1992; Johnson, 1994; Johnson, 1995; Cran and Johnson, 1996). Emphasis in this review will be on recent work.

From a theoretical standpoint, the phenotypic sex of an animal that will be produced by a spermatozoon or embryo can be determined most accurately at the gene level. Even at this level, there will be occasional errors due to mutations. Although presence or absence of the Sry gene (Koopman et al., 1991) is the primary determinant of phenotypic sex, a cascade of additional genetic events is required to produce the specified sexual structures. This cascade, which involves genes on autosomes and sex chromosomes, is poorly understood in mammals (Bogan and Page, 1994).

Sex-chromosomal composition is another level at which sex potentially can be detected; functionally, this is the level at which nature operates. Several genes that appear unrelated to sex determination are transmitted incidentally with the sex-determining arm (non-pseudoautosomal region) of the $Y$ chromosome (for example Greenfield et al,, 1996). There is debate on whether determining sex-chromosomal composition is a genetic or phenotypic trait. This is relevant, for example, when measurement of total DNA content is the method of identifying an $X$ or $Y$ chromosome in a spermatozoon.

The most studied and used methods for attempting sexing are phenotypic, and range from measuring enzyme activity of embryos (Williams, 1986) to determining parameters of sperm motion (Penfold et al., 1998). Sexing fetuses by skilled technicians using ultrasound approaches $99 \%$ accuracy by 2 months of gestation in humans, cattle and horses (Curran and Ginther, 1991). Although this special case concerns recording rather than selecting, many find information on fetal sex valuable in for example experimentation, merchandizing, management and planning. Occasionally this approach is used together with abortion of fetuses of the undesired gender to control the sex of offspring produced.

\section{Sexing Preimplantation Embryos}

The many procedures for analysing the sex of preimplantation embryos are summarized in Table 1 , Results, of course, are obtained too late to choose the sex except by discarding the sex that is less valuable to the client. This is not merely a trite observation. For example, many embryo transfer practitioners fail to use or promote procedures for sexing embryos because their income from a particular donor animal decreases considerably if half of the embryos are discarded.

The only method of sexing embryos in routine commercial use is to biopsy embryos, usually with tools connected to a micromanipulator, followed by amplification of Y-chromosome-specific DNA in the sample using the polymerase chain reaction (PCR) and appropriate primers (Bondioli et al., 1989; Herr and Reed, 1991; Thibier and Nibart, 1995). Obtaining the biopsy is art and science. Ideally, only a few cells are removed without damaging the embryo and without contamination by accessory spermatozoa attached to or embedded in the zona pellucida. In practice, about ten cells are generally excised. There are several species-specific aspects to biopsy; for example, compromising the capsule of the equine blastocyst can decrease pregnancy rates.

There are two options for selecting Y-chromosome-specific DNA: single copy sequences such as Sry, or sequences with no known function that are repeated hundreds to thousands of times. Mammalian Y chromosomes abound with such species-specific repeats; they have the advantage of having been amplified even before any PCR procedures. Unfortunately, different sequences must be identified for each individual species.

Once potential Y-chromosome-specific DNA has been amplified by PCR, the most thorough identification procedure would be gel electrophoresis followed by Southern blotting. This is rarely done in practice. The most common procedure is to observe the gel for the presence or absence of the correct size band of DNA, as revealed by ethidium bromide intercalated into the DNA (visualized with UV light). Often a positive control for amplified DNA is engineered into the system: for example, an additional set of PCR primers for each sample can be incorporated that is specific to autosomes or the X chromosome (Thibier and Nibart, 1995). This procedure confirms that DNA from 
Table 1. Procedures for sexing preimplantation embryos

\begin{tabular}{|c|c|c|c|c|}
\hline Method & Sexable (\%) & Accuracy & Reference & Comments \\
\hline Biopsy; sex chromatin & $40-50$ & $>95 \%$ & $\begin{array}{l}\text { Gardner and } \\
\text { Edwards, } 1968\end{array}$ & First method \\
\hline Biopsy; karyotype & $30-70$ & $>95 \%$ & Hare ef al., 1976 & $\begin{array}{l}\text { First definitive } \\
\text { method }\end{array}$ \\
\hline $\begin{array}{l}\text { Compaction response to } \\
\text { antibodies to male-specific } \\
\text { antigen }\end{array}$ & $90-95$ & $\sim 75 \%$ & Utsumi et al., 1984 & Subjective \\
\hline $\begin{array}{l}\text { Male embryos develop } \\
\text { more rapidly in vitro }\end{array}$ & $60-70$ & $\sim 70 \%$ & Tsunoda et al., 1985 & $\begin{array}{l}\text { Depends on } \\
\text { culture system }\end{array}$ \\
\hline Gene dosage of G6PD & $60-70$ & $-65 \%$ & Williams, 1986 & $\begin{array}{l}\text { Narrow } \\
\text { window; } \\
\text { subjective }\end{array}$ \\
\hline $\begin{array}{l}\text { Biopsy; Y-specific } \\
\text { in situ hybridization }\end{array}$ & $80-90$ & $>90 \%$ & West et al., 1987 & Tedious \\
\hline $\begin{array}{l}\text { Immunological detection } \\
\text { of male-specific antigen }\end{array}$ & $80-85$ & $-80 \%$ & Anderson, 1987 & $\begin{array}{l}\text { No biopsy } \\
\text { required; } \\
\text { subjective }\end{array}$ \\
\hline $\begin{array}{l}\text { Biopsy; Y-specific DNA, } \\
\text { electrophoresis }\end{array}$ & $90-95$ & $>95 \%$ & Bondioli et al., 1989 & $\begin{array}{l}\text { Used } \\
\text { commercially }\end{array}$ \\
\hline $\begin{array}{l}\text { Biopsy; Y-specific DNA, } \\
\text { no electrophoresis }\end{array}$ & $90-95$ & $\sim 95 \%$ & Bredbacka et al., 1995 & Being refined \\
\hline
\end{tabular}

the biopsy was in fact placed into the assay vessel and that the entire system was functioning. Without such a control, system failure cannot be distinguished from a female embryo. Note that great care is required for these procedures because of the extreme sensitivity of PCR; just one contaminating cell or contaminating DNA from serum can lead to an incorrect diagnosis. An example of precautions taken to avoid contamination is to have all reagents in a single container throughout the process, with the containers prepared in advance in a controlled environment, and with quality-control sampling before use.

An improvement to the technique just described eliminates the need for gel electrophoresis, simplifying the sexing procedure and shortening the time required (Bredbacka et al., 1995). In this case, PCR primers are made that bind to multiple sites along a highly repeated $(\sim 60000 \times)$ bovine sequence of Y-chromosome-specific DNA. Concentrations of PCR primers and nucleotides and other PCR conditions are such that large quantities of DNA are produced by PCR if this sequence is present.

The endpoint of this assay is simply to observe the PCR reaction mix, which contains ethidium bromide, under UV light. Tubes containing the Y-specific sequence will have large quantities of DNA, and thus are pink; those without $Y$-specific sequence just have DNA from the biopsy and have barely any colour. Numerous unpublished improvements have been made to the original paper by Bredbacka et al. (1995); a control to distinguish system failure from a female embryo has not yet been published for this method.

All methods of sexing embryos have limitations. Those based on PCR of Y-chromosome-specific sequences are very accurate, but require biopsy of embryos. The biopsy process is time consuming, and an occasional embryo is lost or destroyed in the process; however, there is little effect on pregnancy rates as practised in cattle, with the possible exception of cryopreserved, biopsied embryos.

The methods involving antibodies to male-specific antigen (sometimes termed $\mathrm{H}-\mathrm{Y}$ antigen, perhaps incorrectly) are subjective, and reagents are not commercially available. A major drawback of the method is that the molecule being detected is unknown, although it appears to be conserved 
across species. Moreover, it is easily detected only between the eight-cell and early blastocyst stages (Anderson, 1987), probably because the gene is not expressed in early stages, and the gene product is masked or internalized after the early blastocyst stage. The molecule seems to be a very weak antigen, requiring various immunological tricks to raise usable antibodies (Anderson, 1987). A candidate gene is the H-Y antigen (Wang et al, 1995); this molecule differs in only two amino acids from the female antigen in humans (but see Greenfield et al., 1996), which would explain why malespecific antibodies are so difficult to produce. Possibly a renewed effort in this area based on antibodies to a synthetic sequence would lead to a reasonably reliable procedure for sexing embryos without the need for biopsy.

The other methods listed in Table 1 have limitations of subjectivity, impractical timing, low accuracy, and/or require too much time to be practical. Investing resources for improved methods may be risky from a commercial standpoint because reliable methods of sexing spermatozoa might make sexing embryos obsolete. However, it is quite possible that genotyping biopsies of embryos for alleles of economic interest will become a major animal breeding tool, in which case confirming sex may simply become important ancillary information, even with sexed semen.

\section{Sexing Spermatozoa}

\section{Theoretical considerations}

From an evolutionary perspective, there is a clear theoretical advantage to a 50:50 sex ratio (Fisher, 1930). In most cases, species with a 50:50 sex ratio will out-compete those in the same ecological niche that do not have a 50:50 sex ratio, although the optimal sex ratio produced by individual wildlife parents may vary because of a variety of environmental and sociological factors (reviewed by Gosling, 1986). In mammals, numbers of X-and Y-chromosome-bearing spermatozoa produced are equal as a consequence of the way that chromosomes segregate at meiosis. One problem remains, that is to ensure that $\mathrm{X}$ - and $\mathrm{Y}$-chromosome-bearing spermatozoa have an equal chance of fertilizing an oocyte.

$\mathrm{X}$ - and $\mathrm{Y}$-chromosome-bearing spermatozoa are identical phenotypically and this ensures a 50:50 sex ratio; if the spermatozoa are not different from each other, each spermatozoon will have an equal chance of fertilizing the ovum. With rare exceptions such as the $T / t$ complex in mice (Silver, 1985), this principle applies to all genes, not just to those determining sex; that is, the phenotype of the spermatozoa does not vary with the haploid genotype. Thus, within each meiotic event, the four spermatozoa produced from a primary spermatocyte are fairly homogeneous phenotypically.

Note that if this were not true, there would frequently be a distortion from a 50:50 ratio of transmitting alleles. Conceivably, a heterozygous male for black/red colour would not produce half black and half red offspring when mated to red females if there were chance pleiotropic effects of these alleles on sperm function; many genes affect sperm function. Thus, although there are great differences between males in sperm phenotype, including ferfilizing potential, velocity of swimming, and ability to compete (demonstrated convincingly and repeatedly in heterospermic insemination experiments; for example Nelson et al., 1975; Dziuk, 1996), within males, alleles usually are transmitted randomly. There is not complete success in achieving a 50:50 allele distribution within males; for example, in most mammals a slight excess of males is produced consistently due to mechanisms that remain unexplained. The distorted ratios of transmitting the autosomal $\mathrm{T} / \mathrm{t}$ alleles represent another failure (Silver, 1985). However, the exceptions are very rare and the distortions generally slight. In addition it should be remembered that $\mathrm{X}$-chromosome-bearing spermatozoa are male, not female, tissue.

Four major mechanisms ensure that spermatozoa within a male are phenotypically equivalent. The first is sex-chromosome specific. During post-meiotic manufacture of spermatozoa, a process that takes weeks to accomplish, the sex chromosomes are in a heterochromatic sex vesicle, and there is little expression of genes on these chromosomes (Meistrich, 1982; Schmid, 1985). Both X and $Y$ chromosomes are inactive. Because many genes on the $X$ chromosome are essential for cells to live, 
inactivation of the $X$ chromosome requires one of two compensatory ploys: expression of substitute autosomal genes active only during spermatogenesis, or production of required gene products by the Sertoli cells as they carry out their nurse cell functions (Bellvé, 1982).

The second mechanism to enhance phenotypic equivalence of spermatozoa is that developing spermatids are interconnected by cytoplasmic bridges (deKretser and Kerr, 1988). Thus, there is cytoplasmic continuity between X-and Y-chromosome-bearing spermatids. Little is known about the kinetics of information exchange through these cytoplasmic bridges, but some exchange is inevitable (Bellvé, 1982), including mRNA (Braun et al, 1989). Maintenance of these bridges through meiotic cell divisions is shown in Fig. 1.

The third mechanism is limitation of post-meiotic gene expression, particularly in the later stages of sperm formation. Thus, most of the mRNA guiding transformation of a spherical spermatid into a spermatozoon is synthesized in the large primary spermatocyte, which has the diploid (actually duplicated diploid) genome expressing genes, and retained for later use (Hecht, 1993). The primary spermatocyte proceeds through the two meiotic cell divisions, leading to four very similar spermatids, including similar mRNA content (Fig. 1). Although mRNA from some genes continues to be transcribed in the haploid spermatids (which, however, are connected to each other by cytoplasmic bridges), it is at a relatively low level, slowing to near zero as the chromatin in the spermatid nucleus condenses (Bellvé, 1982; Hecht, 1993).

The fourth mechanism of making sperm phenotypically equivalent is to coat their surfaces with secretions of fluids from Sertoli cells and cells of the rete testis, efferent ducts, epididymis, and accessory sex glands (for example Iusem et al., 1989; Amann et al., 1993). Many molecules from these fluids have relatively strong binding characteristics.

To summarize this section, nature goes to great lengths to make spermatozoa within a male uniform phenotypically. Mechanisms include inactivation of sex chromosomes early in the meiotic process, maintaining cytoplasmic continuity among the developing sperm cells, turning off most gene expression once haploid cells are formed, and coating the resulting spermatozoa with numerous molecules. Thus, it would be expected that spermatozoa within a male are similar in size, cell surface properties, and other features. Undoubtedly, within each male there are subtle, mostly intracellular phenotypic differences between spermatozoa with different sex chromosomes, but whether these will be sufficient for practical use is unknown (Howes ef al., 1997). The repeated failures in separating X-and Y-chromosome-bearing spermatozoa (Amann and Seidel, 1982; Howes et al., 1997) attest to success in producing a 50:50 sex ratio by making phenotypically identical spermatozoa. However, there is one substantial phenotypic difference between $\mathrm{X}$ - and $\mathrm{Y}$ chromosome-bearing spermatozoa: there is more DNA in $X$ than in $Y$ chromosomes,

\section{Principles of separating $X$-and $Y$-chromosome-bearing spermatozoa based on DNA content}

Rapid measurement of DNA in single cells became possible with flow cytometry techniques. This was first accomplished for spermatozoa in the early 1980s, and was made even more useful by adding a sorting mechanism to the detection system. This work has been reviewed in detail several times recently (Johnson, 1994, 1995; Cran and Johnson, 1996).

Before 1997, X- and Y-chromosome-bearing spermatozoa from most mammals were analysed and sorted with a standard flow cytometer/cell sorter at rates of approximately 100 spermatozoa s $^{-1}$ of each sex with about $90 \%$ accuracy. The principle is to incubate spermatozoa with the cell membrane-permeable, fluorescing dye Hoechst 33342, which binds quantitatively to AT-rich regions of DNA. Since X-chromosome-bearing spermatozoa have more DNA (about $3.8 \%$ more in cattle) than do Y-chromosome-bearing spermatozoa (Johnson, 1992), when stained they emit a stronger signal when excited by light at the correct wavelength, usually from a laser. The emission signal is amplified, analysed, and a determination made of whether the spermatozoon probably is Xchromosome bearing, Y-chromosome bearing, or ambiguous to the detection system. The majority of spermatozoa are classified as ambiguous, not because of intermediate DNA content, but because of imprecision in the staining and detection procedures.

One difficulty is that the fluorescence signal emitted is highly dependent on the orientation of 


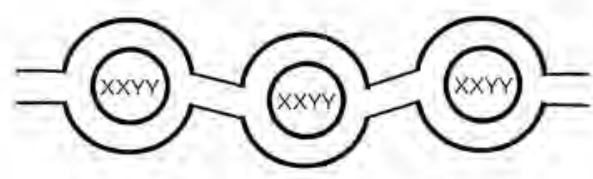

Primary spermatocytes

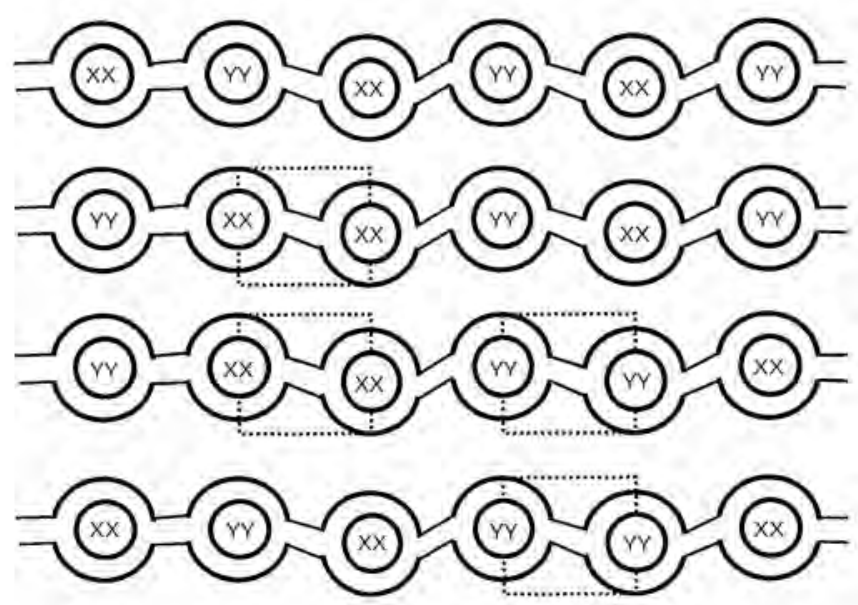

The four possible configurations resulting from divisions of three primary spermatocytes

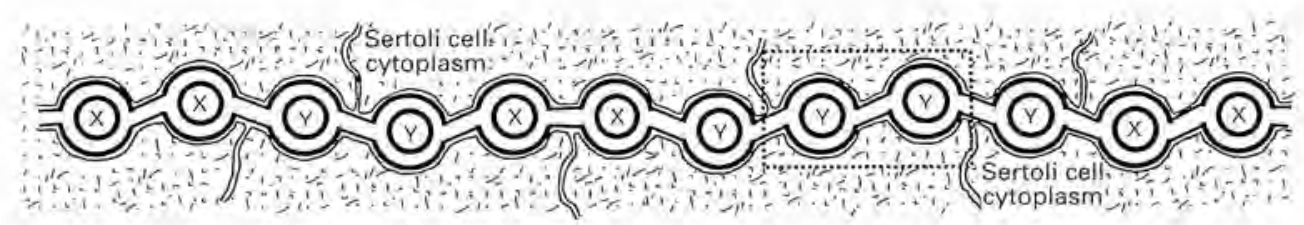

Resulting spermatids (illustrated for last configuration only) showing continuum of Sertoli cells that further affect homogeneity of resulting sperm cells

The boxes indicate the spermatids that will form that are connected to $2 \mathrm{X}$ or $2 \mathrm{Y}$ spermatids

Fig. 1. Segregation of sex chromosomes during meiosis. Depending on the species, up to 128 primary spermatocytes are interconnected by intercellular bridges due to incomplete cell division. Cell death may result in broken bridges and reduce the numbers of germ cells connected. Because centromeres do not divide during the first meiotic division, each secondary spermatocyte will be either of XX or YY sex chromosome composition, never XY. Possibilities of sex chromosome distributions during the first meiotic cell divisions of three interconnected primary spermatocytes are shown. It is not known whether the four possibilities illustrated occur with equal probability. Whatever the configuration, each secondary spermatocyte is connected to one XX and one $\mathrm{YY}$ secondary spermatocyte.

If the four configurations occur at random, excluding ends of sets, when a secondary spermatocyte divides to form spermatids, thee situations would occur with the probabilities indicated in parentheses:

(1) A given spermatid connected to one $X$ - and one $X$-chromosome-bearing spermatid (75\%).

(2) An X-chromosome-bearing spermatid connected to $2 X$-chromosome-bearing spermatids (12.5\%).

(3) A Y-chromosome-bearing spermatid connected to 2 Y-chromosome-bearing spermatids $(12.5 \%)$.

Since the sex chromosomes are inactive transcriptionally, the asymmetry illustrated is of no phenotypic consequence. The course that nature has taken, shutting down transcription of sex 
the spermatozoa, because mammalian spermatozoa are asymmetrical. In practice, a second detector is used to determine orientation, and only those spermatozoa oriented correctly are analysed. Orientation can be regulated in several ways, for example by presenting spermatozoa to the quantifying detector in a ribbon rather than a cylinder of fluid (Gledhill et al., 1982); the paddleshaped ruminant spermatozoa tend to orient with their flat plane in the plane of the ribbon, although this is by no means a perfect relationship.

The sexing process is more productive if dead or deteriorating spermatozoa, which frequently constitute more than $10 \%$ of the ejaculate, depending on the species and the individual male, are not collected. This is accomplished by adding a molecule to the medium containing spermatozoa that is excluded from the sperm cytoplasm by a healthy plasma membrane, but that readily diffuses into the cytoplasm of spermatozoa with compromised cell membranes. This molecule quenches fluorescence of Hoechst 33342 that is bound to DNA, and thus marks dead spermatozoa. Propidium iodide and some food-colouring dyes are examples of such molecules (Johnson et al., 1998).

\section{What is new in flow cytometry/cell sorting of spermatozoa for DNA content?}

The number of droplets encasing spermatozoa produced by flow cytometers per unit time increases as input pressure of the fluid stream increases. A new generation of flow cytometers has recently been developed that operate at higher pressure than earlier models, resulting in more rapid throughput and droplet production rates approaching $10^{5} \mathrm{~s}^{-1}$. Some of these also have improved electronics; a few microseconds difference in accomplishing each of the various steps of signal detection and processing can make a great difference in performance of such instruments. We have been using one such instrument routinely to obtain over 600 live spermatozoa $\mathrm{s}^{-1}$ of each sex (Seidel et al., 1998). Another improvement is in nozzle design (Johnson et al., 1998). One principle exploited is to move the detection system closer to the nozzle where there are oriented spermatozoa so that a higher percentage of spermatozoa remain oriented with their flat side toward the quantifying detector. Johnson et al. (1998) reported sorting rates between 1000 and 1500 spermatozoa s-1 of each sex at about $90 \%$ accuracy using this approach.

Further refinements of flow cytometers and cell sorters for sexing spermatozoa are inevitable. New detection systems (Sharpe et al., 1997) might completely circumvent the problem of orientation of asymmetrical cells. Slit-scan procedures may solve the problem of overlap in distributions of signal strength of $X$-and $Y$-chromosome-bearing spermatozoa that occurs even when spermatozoa are in ideal orientation (Rens et al, 1996).

There are theoretical limits to the number of spermatozoa that can flow past a detector per unit of time without obfuscating the signals of the individual spermatozoa. Similarly, a drop exiting the system may contain two spermatozoa with opposite sex-chromosomes; such drops are discarded. Perhaps such limitations will set a theoretical upper limit to sorting in the range of $5-10 \times 10^{3}$ live spermatozoa s ${ }^{-1}$ of each sex with flow cytometers. It is possible to resort to parallel processing $i$ with individual components serving several streams, akin to one fuel pump for a multi-cylinder internal combustion engine. Ideally, systems for sexing spermatozoa will evolve that do not require evaluation of spermatozoa one at a time. Up to the present time, no such system has proven reliable.

\section{Special problems and benefits of sorting spermatozoa with flow cytometers/cell sorters}

Incubating spermatozoa with Hoechst 33342, which has a high affinity for AT-rich regions of DNA, exposing them to laser light, pumping them through fine tubing at high pressure so that they exit a small orifice at about $100 \mathrm{~km} \mathrm{~h}^{-1}$, and storing them at ambient temperature for hours as numbers accumulate are processes that are not conducive to sperm health. We have evaluated sorted

chromosomes and limiting transcription of autosomes post-meiotically circumvents potential problems of transferring excess genetic information from $X$ or $Y$ chromosomes to some spermatids via intercellular bridges. Note that all germ cells are embedded in Sertoli cell cytoplasm, another mechanism for making sperm cell membranes identical (illustrated for spermatids only). 
spermatozoa using many different procedures and invariably find that spermatozoa are damaged to some extent by the sexing procedures described. However, it is unclear which aspects of the process cause damage. To what extent such damage can be decreased by improved techniques or overcome by compensatory numbers of spermatozoa or other means is unknown. However, it is clear that pregnancy rates are not compromised greatly with sorted spermatozoa, even though they have sustained some damage (Seidel et al., 1998).

A phenomenon documented by McNutt and Johnson (1996) is that the first cell cycle is delayed in rabbit embryos fertilized by spermatozoa treated with Hoechst 33342 . The mechanism involved is unknown, but could be interference of the dye molecules as DNA is replicated or transcribed. This might be responsible for lowered pregnancy rates with sexed spermatozoa. Fortunately, no increased incidence of abnormalities has been noted in the hundreds of offspring of various species produced by sexed semen (Cran and Johnson, 1996). However, rigorous tests of normality using hundreds of offspring in controlled trials involving multiple generations remain to be done.

All is not negative. There are theoretical benefits to using spermatozoa for insemination that are processed by the methods described. For example, dead spermatozoa as determined by dye exclusion are eliminated. In addition, some aneuploidies, including diploid spermatozoa, are eliminated via gating of fluorescence signals during the sorting process. Finally, it is possible that in vitro capacitation of flow-sorted spermatozoa will be facilitated.

\section{Artificial insemination with sexed semen}

Although impressive improvements have been made in flow cytometer/cell sorter performance, even the most optimistic projections result in insufficient spermatozoa throughput to use sexed semen with procedures for routine artificial insemination. Current sperm sorting rates are more than adequate, however, for procedures such as in vitro fertilization (Cran et al., 1993) and intracytoplasmic sperm injection.

In some species, laparoscopic insemination with low numbers of spermatozoa may be feasible (for example, sheep; Cran et al., 1997). In other species, artificial insemination procedures can probably be modified to achieve acceptable pregnancy rates with a smaller number of spermatozoa than are used routinely. For example, we have achieved reasonable pregnancy rates in heifers using only $5 \times 10^{5}$ total (unsexed) spermatozoa per cryopreserved insemination dose (Seidel et al., 1996). In these and related studies with unfrozen semen (Seidel et al., 1997), we inseminated spermatozoa in 0.1-0.2 $\mathrm{ml}$ into the uterine horns using atraumatic, side-opening sheaths. Which, if any, of these modifications to conventional insemination procedures contributes to efficacy was not studied, and results may not apply to all bulls. Den Daas et al. (1998) found that the decrease in fertility as numbers of spermatozoa frozen per insemination dose were lowered varied markedly among bulls; for some bulls fertility was normal at the lowest numbers of spermatozoa tested, about $2 \times 10^{6}$ spermatozoa per insemination into the uterine body.

In two recent studies, we combined procedures for inseminating low doses of semen with the flow sorting procedures described earlier. In the first study (Seidel et al., 1997), a conventional flow cytometer providing about 100 spermatozoa s ${ }^{-1}$ of each sex was used. The bulls, flow cytometer, and cattle to be inseminated were located great distances from each other, so coordination of procedures was imperfect. Success with this liquid, sexed semen varied among replicates from $0 / 38$ to $9 / 20$ pregnant to term; 14 of the 17 calves produced in this study were of the predicted sex. In this preliminary trial, there was a strong suggestion of bull-to-bull variation in pregnancy rates with low doses of sexed semen. In addition, the pregnancy rate declined markedly if the interval from sorting to insemination exceeded $12 \mathrm{~h}$.

The second study (Seidel et al., 1998) was logistically less demanding. A high performance flow cytometer and cell sorter provided 500-600 live spermatozoa $\mathrm{s}^{-1}$ of each sex, and the cattle were only $200 \mathrm{~km}$ distant from the instrument. The pregnancy rate to term after insemination of doses of $3 \times 10^{5}$ live (total) spermatozoa selected to have $X$ chromosomes was $42 \%(n=45)$; for the liquid semen control of $3 \times 10^{5}$ motile spermatozoa per insemination, the pregnancy rate was $54 \%(n=28)$; and for the frozen semen control of $15.6 \times 10^{6}$ motile spermatozoa per dose after thawing, it was $52 \%(n=29$; 
Seidel et al., 1998). These data were balanced across three bulls and two inseminators. Eighteen of 19 calves born from sexed semen were females. Only one sexed and one control pregnancy detected by ultrasonography at 31-34 days after insemination did not develop to term, indicating that pregnancy wastage was minimal after 1 month of gestation. Although fertility of this sexed semen was only about $80 \%$ of controls, these results are promising. Early data from a field trial in progress (Schenk et al., unpublished) indicate that pregnancy rates after artificial insemination of heifers with sexed, frozen semen with twice the number of spermatozoa $\left(10^{6}\right.$ per dose) to compensate for damage due to cryopreservation were virtually identical to those using sexed, unfrozen semen $\left(5 \times 10^{5}\right.$ spermatozoa per dose).

\section{Future prospects for applying sexed semen technology}

There are many studies that convincingly demonstrate that it is possible to change the sex ratio at conception to approximately $90 \%$ of the desired sex by sorting spermatozoa on the basis of DNA content using flow cytometer and cell sorter technology (for example Johnson et al., 1989; Cran et al., 1993; Seidel $\mathrm{et}$ al., 1998). Even with sorting rates of $1 \times 10^{3}-1.5 \times 10^{3}$ live spermatozoa $\mathrm{s}^{-1}$ of each sex, this remains primarily a research technique, with possible niche applications for in vitro fertilization and artificial insemination of very valuable breeding animals.

Flow cytometer and cell sorter equipment is very expensive, and requires skilled personnel for operation. To date, general purpose research instruments have been used. Possibly flow cytometers and cell sorters specifically designed for sorting spermatozoa would be simpler to operate, less expensive, and more efficacious. For serving mass agricultural markets, it would seem that instruments sorting a minimum of 10-20 insemination doses of semen $\mathrm{h}^{-1}$ of each sex would be required.

Even with optimistic assumptions, sorting spermatozoa one at a time as they flow past a detector is not an appealing approach for agricultural applications. This is a difficult process to scale up. Perhaps other approaches will be developed. Many patents have been issued for sexing semen (summarized by Ericsson and Glass, 1982), although the majority are of little value. Before the early 1980 s, there was no reliable method for determining whether a particular technique to sex spermatozoa was efficacious, even if spermatozoa were killed, other than inseminating many animals for each assay. The expense and time required for obtaining such information for practical purposes precluded developing and improving sperm sexing methodology. Flow cytometry provides a robust tool to test, within minutes, other approaches to sexing semen. To date, all alternative approaches to sexing semen examined have failed this quality control test (Gledhill et al., 1982; Johnson, 1988).

With flow cytometry or molecular approaches such as fluorescence-in situ hybridization for assays and our rapidly increasing knowledge of molecular and cellular biology of spermatozoa, more practical methods of sexing semen might become available eventually. However, for the foreseeable future, the only reliable method for sexing spermatozoa while maintaining fertility is with a flow cytometer and cell sorter.

\section{Conclusions}

Thousands of bovine preimplantation embryos are sexed annually on a commercial basis with $>95 \%$ accuracy and with little decrease in pregnancy rates, by subjecting an embryonic biopsy to the polymerase chain reaction. Other methods of sexing embryos, while accurate to various degrees, remain limited to research applications.

There is only one efficacious method of sexing spermatozoa that does not kill them-quantifying DNA by flow cytometry and cell sorting after exposing spermatozoa to a fluorescing DNA-binding dye. Sorting techniques are improving rapidly; currently it is possible to sort more than $2 \times 10^{3}$ live spermatozoa per second, half enriched for each sex chromosome. Sorted spermatozoa are damaged to some extent with current procedures, but hundreds of apparently normal offspring have been 
produced. Sexing spermatozoa is still a research technique, but commercialization for artificial insemination may occur in the near future.

Drs Rupert Amann and David Cran critically read the manuscript and provided helpful comments. Research from our laboratory has been supported in part by XY, Inc, Fort Collins, Colorado, the Colorado State University Experiment Station, the Colorado Advanced Technology Institute, Genex, Inc., and the National Association of Animal Breeders.

\section{References}

Amann RP (1989) Treatment of sperm to predetermine sex Theriogenology $3149-60$

Amann RP and Seidel GE, Jr (1982) Prospects For Sexing Mammatian Sperm. Colorado Associated University Press, Boulder, $\mathrm{CO}$

Amann RP, Hammerstedt RH and Veeramachaneni DNR (1993) The epididymis and sperm maturation: a perspective Reproduction, Fertility and Development 5 361-381

Anderson GB (1987) Identification of embryonic sex by detection of $\mathrm{H}-\mathrm{Y}$ antigen Theriogenology 27 81-97

Bellvé AR (1982) Biogenesis of the mammalian spermatozoan. In Prospects for Sexing Mammalian Sperm pp 69-102 Ed. RP Amann and GE Seidel, Jr. Colorado Associated University Press, Boulder, CO

Betteridge KJ, Hare WCD and Singh EL (1981) Approaches to sex selection in farm animals. In New Technologies in Aninul Breeding pp 109-125 Ed. BG Bracket, GE Seidel, Jr and SM Seidel. Academic Press, New York

Bogan JS and Page DC (1994) Ovary? Testis? A mammalian dilemma Cell 76 603-607

Bondioli K (1992) Embryó sexing: a review of current techniques and their potential for commercial application in livestock production Journal of Animal Science 70 (Supplement 2) 19-29

Bondioli KR, Ellis SB, Prior $\mathrm{JH}_{t}$ Williams MW and Harpold MM (1989) The use of male-specific chromosomal DNA fragments to determine the sex of preimplantation bovine embryos Theriogenology 31 95-104

Braun RE, Behringer RR, Peschon JJ, Brinster RL and Palmiter RD (1989) Genetically haploid spermatids are phenotypically diploid Naine 337 373-376

Bredbacka P, Kankaanpää A and Peippo J (1995) PCR-sexing of bovine embryos: a simplified protocol Theriogenology 40 $167-176$

Burfening PJ, Kress DD, Friedrich RL and Vaniman DD (1978) Phenotypic and genetic relationships between calving ease gestation length, birth weight and pre-weaning growth Journal of Animal Science 47 595-600

Cran DG and Johnson LA (1996) The predetermination of embryonic sex using flow cytometrically separated $\mathrm{X}$ and Y spermatozoa Human Reproduction Update 2 355-363

Cran DG, Johnson LA, Miller NGA, Cochrane D and Polge C (1993) Production of calves following separation of $X$ and $Y$ chromosome bearing sperm and in vitro fertilization Veterinary Record $13240-41$

Cran DG, McKelvey WAC, King ME, Dolman DF, McEvoy TG, Broadbent PJ and Robinson JJ (1997) Production of lambs by low dose intrauterine insemination with flow cytometrically sorted and unsorted semen Theriogenology 47267 (Abstract)

Curran S and Ginther OJ (1991) Ultrasonic determination of fetal gender in horses and cattle under farm conditions Theriogenology 36 809-814
deKretser DM and Kerr JB (1988) The cytology of the testis. In The Physiology of Reproduction. Vol. 1. pp 837-932 Ed. E Knobil and JD Neill. Raven Press, New York

den Daas JHG, De Jong G, Lansbergen LMTE and Van WagtendonkDe Leeuw AM (1998) The relationship between the number of spermatozoa inseminated and the reproductive efficiency of individual dairy bulls Joumal of Dairy Science 81 1714-1723

Dziuk PJ (1996) Factors that influence the proportion of offspring sired by a male following heterospermic insemination Animal Reproduction Scicnce 43 65-88

Ericsson RJ and Glass RH (1982) Functional differences between sperm bearing the $X$ or $Y$ chromosome. In Prospects for Sexing Mamusnlian Spern pp 201-211 Ed. RP Amann and GE Seidel, Jr. Colorado Associated University Press, Boulder, $\mathrm{CO}$

Fisher RA (1930) The Genetical Theory of Natural Selection. Oxford University Press, Oxford

Gardner RL and Edwards RG (1968) Control of the sex ratio at full term in the rabbit by transferring sexed blastocysts Nature 218 346-348

Gledhill BL, Pinkel D, Garner DL and Van Dilla MA (1982) Identifying $X$ - and $Y$-chromosome-bearing sperm by DNA content: retrospective perspectives and prospective opinions. In Prospects for Sexing Mammalian Sperm pp 177-191 Ed. RP Amann and GE Seidel, Jr. Colorado Associated University Press, Boulder, CO

Gosling LM (1986) Selective abortion of entire litters in the Coypu: adaptive control of offspring production in relation to quality and sex Anterican Naturalist 127 772-795

Greenfield H, Scott D, Pennisi D, Ehrman I, Ellis P, Cooper L, Simpson E and Koopman P (1996) An H-YDb epitope is encoded by a novel $Y$ chromosome gene Nafure Genetics 4 $474-478$

Hare WCD, Mitchell D, Betteridge KJ, Eaglesome MD and Randall GCB (1976) Sexing two-week old bovine embryos by chromosomal analysis prior to surgical transfer: preliminary methods and results Theriogenology 5 243-253

Hecht NB (1993) Gene expression during male germ cell development. In Cell and Molecular Biology of the Testes pp 400-432 Ed. C Desjardins and L Ewing. Oxford University Press, Oxford

Herr CM and Reed KC (1991) Micromanipulation of bovine embryos for sex determination Theriogenology 35 45-54

Howes EA, Miller NGA, Dolby $C_{r}$ Hutchings A, Butcher GW and Jones R (1997) A search for sex-specific antigens on bovine spermatozoa using immunological and biochemical tectuniques to compare the protein profiles of $X$ and $Y$ chromosome-bearing sperm populations separated by fluorescence-actiyated cell sorting Journal of Reproduction and Fertility $110195-204$

Iusem ND, Pineiro L, Blaquier JA and Belocopitow E (1989) Identification of a major secretory glycoprotein from rat 
epididymis: interaction with spermatozoa Biology of Reproduction 40 307-316

Johnson LA (1988) Flow cytometric determination of sperm sex ratio in semen purportedly enriched for $\mathrm{X}$-and $\mathrm{Y}$-bearing sperm Theriogenology 29265 (Abstract)

Johnson LA (1991) Sex preselection in swine: altered sex ratios in offspring following surgical insemination of flow sorted $\mathrm{X}$ and $\mathrm{Y}$ chromosome bearing sperm Reproducfion in Donestic Animals 26 309-314

Johnson LA (1992) Gender preselection in domestic animals using flow cytometrically sorted sperm Journal of Aminal Science 70 (Supplement 1) 8-18

Johnson LA (1994) Isolation of X-and Y-bearing sperm for sex preselection Oxford Reviezus of Reproductive Biology 16 303-326

Johnson LA (1995) Sex preselection by flow cytometric separation of $X$ and $Y$ chromosome-bearing sperm based on DNA difference: a review Reproduction, Fertility and Development 7 893-903

Johnson LA, Flook JP and Hawk HW (1989) Sex preselection in rabbits: live births from $X$ and $Y$ sperm separated by DNA and cell sorting Biology of Reproduction 41 199-203

Johnson LA, Welch GR, Rens W and Dobrinsky JR (1998) Enhanced flow cytometric sorting of mammalian $X$ and $Y$ sperm: high speed sorting and orienting nozzle for artificial insemination Theriogenology 49361 (Abstract)

Kiddy CA and Hafs HD, Eds (1971) Sex Ratio af Birth-Prospects for Control. American Society for Animal Science, Savoy, IL

Koopman P, Gubbay J, Vivian N, Goodfellow P and Lovell-Badge R (1991) Male development of chromosomally female mice transgenic for SRY Nature 351 117-121

Levinson G, Keyvanfar K, Wu JC, Fugger EF, Fields RA, Harton GL, Palmer FT, Sisson ME, Starr KM, Dennison-Lagos L, Calvo L, Sherins RJ, Bick D, Schulman JD and Black SH (1995) DNAbased $\mathrm{X}$-enriched sperm separation as an adjunct to preimplantation genetic testing for the prevention of $X$ linked disease Molecular Human Reproduction 10 979-982

McNutt TL and Johnson LA (1996) Flow cytometric sorting of sperm: influence on fertilization and embryo/fetal development in the rabbit Molectilar Reproduction and Development 43 261-267

Meistrich ML (1982) Events of meiosis, spermiogenesis and post-meiotic gene expression related to haploid gene expression. In Prospects for Sexing Mammalian Sperm pp 103-106 Ed. RP Amann and GE Seidel, Jr. Colorado Associated University Press, Boulder, CO

Nelson LD, Pickett BW and Seidel GE, Jr (1975) Effect of heterospermic insemination on fertility of cattle Tourval of Animal Science 40 1124-1129

Penfold LM, Holt C, Holt WV, Welch GR, Cran DG and Johnson LA
(1998) Comparative motility of $X$ and $Y$ chromosomebearing bovine sperm separated on the basis of DNA content by flow sorting Molecular Reproduction and Developwent 50 323-327

Rens W, Welch GR, Houck DW, van Oven CH and Johnson LA (1996) Slit-scan flow cytometry for consistent high resolution DNA analysis of X-and $\mathrm{Y}$-chromosome bearing sperm Cytometry 25 191-199

Schmid M (1985) Arrangement of the $Y$ chromosome in interphase and metaphase cells. In The Y Chromosome, Part A: Basic Characteristics of the $Y$ Chromosome pp 17-61. AR L.iss, New York

Seidel GE, Jr (1988) Sexing mammalian sperm and embryos Proceedings of the 11th International Congress on Animal Reproduction and Artificial Insemination (Dublin) 5 136-144

Seidel GE, Jr, Allen CH, Brink Z, Holland MD and Cattell M-B (1996) Insemination of heifers with very low numbers of frozen spermatozoa Journal of Animal Science 74 (Supplement 1) 235 (Abstract)

Seidel GE, Jr, Allen CH, Johnson LA, Holland MD, Brink Z, Welch GR, Graham JK and Cattell M-B (1997) Uterine horn insemination of heifers with very low numbers of nonfrozen and sexed spermatozoa Theriogenology 48 1255-1264

Seidel GE, $\mathrm{Jr}_{\mathrm{r}}$ Herickhoff LA, Schenk JL, Doyle SP and Green RD (1998) Artificial insemination of heifers with cooled, unfrozen sexed semen Theriogenology 49365 (Abstract)

Sharpe JC, Schaare PN and Kumemeyer R (1997) Radially symmetric excitation and collection optics for flow cytometric sorting of asymmetrical cells Cytometry 29 363-370

Silver LM (1985) Mouse t haplotypes Annual Review of Genetics 19 179-208

Thibier M and Nibart M (1995) The sexing of bovine embryos in the field Theriogenology 43 71-80

Tsunoda Y, Tokunaga T and Sugie T (1985) Altered sex ratio of live young after transfer of fast- and slow-developing mouse embryos Gamete Research 12 301-304

Utsumi K, Satoh E and Yuhara M (1984) Sexing of mammalian embryos exposed to H-Y antisera Proceedings of the 10ith International Congress on Animal Reproduction and Artificial Insemination (Urbana) 2234

Wang W, Meadows LR, den Hahn JMM, Sherman NE, et al. (1995) Human H-Y: a male specific histocompatibility antigen derived from the SMCY protein Science 269 1588-1590

West JD, Godsen JR, Angell RR, Hastie ND, Thatcher SS, Glasier AF and Baird DT (1987) Sexing the human pre-embryo by DNA-DNA in situ hybridization Lancet 1 1345-1347

Williams T] (1986) A technique for sexing mouse embryos by a visual colorimetric assay of the $\mathrm{X}$-linked enzyme glucose 6-phosphate dehydrogenase Theriogenology 25 733-739 